\title{
Los defectos observables y la garantía de buen funcionamiento en la compraventa*
}

\author{
The observable defects and the proper functioning guarantee \\ in trading \\ Recibido: 05 de junio de 2014 - Revisado: 30 de septiembre de 2014 - Aceptado: 06 de noviembre de 2014
}

Jorge Oviedo Albán**

\section{Resumen}

El presente artículo analiza dos mecanismos legales de protección al comprador contenidos en el Código de Comercio colombiano, paralelos a las acciones edilicias por vicios ocultos en la compraventa, que son: la garantía por defectos observables a la entrega y la garantía de buen funcionamiento. El autor examina la forma deficiente como tales acciones se encuentran en el Código, lo que es consecuencia de un régimen fragmentado y disperso de actuaciones por cumplimientos defectuosos en las legislaciones de derecho privado. Propone una reinterpretación de tales actos desde la perspectiva de la falta de conformidad que se basan en un sistema unificado de remedios por incumplimiento, conceptos consagrados en los instrumentos modernos de derecho contractual.

\section{Palabras clave}

Compraventa, falta de conformidad, defectos observables, garantía de buen funcionamiento.

\begin{abstract}
This paper discusses two legal mechanisms for buyer's protection contained in the Colombian Commercial Code, parallel to building regulations, because of hidden defects in the sale, which are: guarantee by observable defects at delivery and guarantee for proper functioning. The author analyzes the poor way such actions are enshrined in the Code as a consequence of a fragmented and dispersed regime for defective compliance actions in the laws of Private Law. This paper proposes a reinterpretation of such actions from the perspective of the lack of conformity that is based on a unified system of remedies for breach, concepts embodied in modern instruments of contract law.
\end{abstract}

\section{Keywords}

Sale, nonconformity, observable defects, proper operation, guarantee.

\footnotetext{
"Este trabajo forma parte del proyecto de investigación "La garantía por vicios ocultos en la compraventa", auspiciado por la Universidad de La Sabana, Bogotá, Colombia.

** Doctor en Derecho y magíster en Derecho Privado por la Universidad de los Andes (Santiago de Chile). Abogado y especialista en Derecho Comercial por la Pontificia Universidad Javeriana (Bogotá). Miembro del Colegio de Abogados Comercialistas de Bogotá. Miembro de la Académie Internationale de Droit Comparé y de la Société de Législation Comparée (París). Profesor de Derecho Civil y Comercial y director de la maestría en Derecho de la Empresa y de los Negocios en la Universidad de La Sabana, Bogotá, Colombia.

Correo electrónico:

jorgeoa@unisabana.edu.co
} 


\section{Introducción}

Según el concepto de contrato de compraventa establecido en el artículo 905 del Código de Comercio colombiano, el vendedor asume a la perfección del contrato, la obligación de traditar el bien al comprador y entregarlo materialmente. En cuanto a la entrega, como acto material, las partes pueden convenir las circunstancias de tiempo, modo y lugar en que la misma se efectuará y como reglas supletivas, el Código determina la manera de efectuarla según lo dispuesto en el artículo 923; el tiempo, en el artículo 924 y en cuanto al lugar, debe estarse a lo prevenido en el artículo 1646 del Código Civil, norma que resulta aplicable a lo mercantil conforme a la regla de remisión directa al estatuto de derecho común, consagrada en el artículo 822.

Ahora, la obligación de entrega no se reduce a un mero acto material, pues así el código no lo señale de forma expresa, debe entenderse que sobre el vendedor pesa una obligación de conformidad, de modo que quedará libre cuando la cosa entregada satisfaga las condiciones de cantidad, calidad y tipo pactadas en el contrato (Decocq, Grimaldi, Huet, \& Lécuyer, 2012, p. 213). Como se verá, la falta de conformidad es un concepto admitido en los instrumentos modernos de derecho de contratos, a partir de su consagración en la Convención de las Naciones Unidas sobre los Contratos de Compraventa Internacional de Mercaderías y es "un concepto unitario que pretende describir cualquier desviación de los bienes respecto de las expectativas del comprador en el contrato de compraventa" (Díez-Picazo, Roca, \& Morales, 2002, p. 322; Schwenzer, Hachem, \& Kee, 2012, p. 369; Vaquer, 2011, p. 374). Esta obligación, puede construirse en el derecho colombiano desde varios preceptos, como es el artículo 1627 del Código Civil, que declara el principio de identidad e integridad del pago, al fijar que este se hará de acuerdo con la obligación y que el acreedor no podrá ser obligado a recibir otra cosa que lo que se deba (Abeliuk, 2008, pp. 643-646). En caso en que no se hubiere pactado la calidad, la obligación de conformidad que pesa sobre el vendedor se cumplirá cuando la cosa entregada cumpla con la calidad mediana, tal como lo disponen los artículos 1566 del Código Civil y 914 del Código de Comercio.

Así las cosas, cabría suponer que cuando el vendedor no cumpla la obligación de conformidad, porque la cosa no corresponde a la pactada, en cuanto a cantidad, calidad y tipo; o por defectos sean observables u ocultos o porque el comprador no pueda disponer de ella según lo convenido, este dispondría de las acciones por incumplimiento, a saber: la acción de ejecución del contrato o la declaración de resolución o terminación del contrato, según lo expresado en el artículo 870. Empero, sucede lo contrario: los remedios con que cuenta el comprador ante la infracción de la obligación de conformidad son variados y se encuentran reglamentados de forma dispersa. En efecto, el Código de Comercio colombiano regula entre los artículos 934 a 938 la garantía por vicios ocultos en la compraventa de modo similar a como lo hacen las codificaciones europeolatinoamericanas de los dos últimos siglos basadas en el origen romano de la garantía edilicia (Morales, 1980; Zimmermann, 1996, pp. 311-330), de forma que si la cosa objeto del contrato presentare defectos ocultos, cuya causa sea anterior al contrato y estos fueren graves, en el sentido de impedir o disminuir el uso normal o pactado de la cosa, el comprador pueda interponer la acción redhibitoria para resolver el contrato o una de rebaja de precio, más una eventual indemnización de perjuicios si el vendedor conociere o debiere conocer tales vicios sin informarlo al comprador.

Así mismo, el Código Civil proclama la responsabilidad por vicios ocultos en la compraventa, entre los artículos 1914 a 1927. Como destacan Díez-Picazo et al. (2002), refiriéndose al caso español, el régimen de saneamiento viene a ser especial frente al sistema general de responsabilidad contractual, con consecuencias 
criticables (pp. 322-323). Además, cabe anotar que el régimen aplicable a los cumplimientos defectuosos de la obligación, que no obstante se enuncia en el artículo 1613 del Código Civil y como tal lo destacan algunos autores (Ospina, 2001, p. 95; Valencia \& Ortiz, 2010, p. 373), es un tema que ha pasado casi desapercibido para la doctrina (Vidal, 2007, p. 52). Por el contrario, en el derecho moderno de contratos, se entiende que hay incumplimiento cuando el deudor no ejecuta alguna de sus obligaciones contractuales, lo que incluye el cumplimiento defectuoso o tardío. Confróntese, artículo 7.1.1 de los Principios de Unidroit; artículo 8:101 PECL y artículo III. 3:101 DCFR (Carrasco, 2010, p. 863; Díez-Picazo, 2008, p. 654; Nanclares, 2011, p. 177).

Además de las dificultades dogmáticas y prácticas surgidas de esta regulación, consistentes básicamente en tratar de establecer si el vicio oculto es o no al tiempo supuesto de hecho de las acciones generales por incumplimiento y/o de nulidad por error en la sustancia o calidad esencial en el objeto, con las consecuentes teorías propuestas con el fin de dotar al comprador insatisfecho de mayores posibilidades de defensa de sus intereses, con acciones no dependientes de plazos cortos de caducidad o prescripción de tales acciones ${ }^{1}$, en el Código de Comercio colombiano se advierte un fraccionamiento de las normas reguladoras del supuesto de cumplimiento defectuoso de la obligación de entrega, toda vez que además de las reglas sobre vicios ocultos, el estatuto mercantil se ocupa de dotar al comprador de mecanismos de protección por defectos de calidad, cantidad y tipo observables al momento de la entrega y también de una garantía de buen funcionamiento (Aguayo, 2011, pp. 404-405; Caprile, 2008, pp. 56-602; Maza De la, 2012; Mantilla \& Ternera, 2008, p. 300; Morales, 2006a, pp. 97-101; Morales, 2006b, pp. 164167; Pizarro, 2008).

Este artículo, que se apoya en el método dogmático de investigación que incorpora el análisis de normas, doctrina y jurisprudencia incluyendo procesos lógicos de inducción, deducción y síntesis, tuvo por objeto precisar si estas acciones son o no compatibles con el régimen edilicio de protección al comprador para lo cual, se busca aportar elementos interpretativos del régimen vigente que según se verá, presenta varias falencias, por lo que resulta aconsejable que el legislador se ocupe de revisar las normas actuales con el fin de dotar de un sistema armónico y uniforme de remedios al comprador insatisfecho, ante faltas de cantidad, calidad y tipo de la cosa objeto del contrato, tema que en el mundo se ha abierto camino a partir de la Convención de las Naciones Unidas sobre los Contratos de Compraventa Internacional de Mercaderías, concepto que, tal como se planteará al término de este documento, permite englobar tanto a los vicios ocultos como a las situaciones aquí analizadas (Ángel De, 2013, pp. 89-93; Vidal, 2006, pp. 53-71).

Este artículo está dividido en tres partes en armonía con los temas que lo integran. En la primera, se analiza el régimen de defectos de calidad observables al momento de la entrega. Para ello, se procede a establecer el concepto de defectos de calidad y el alcance de las normas que lo regulan (1). Posteriormente, se estudia la relación que este régimen presenta con las acciones por vicios ocultos (2). La segunda aborda el régimen de la garantía de buen funcionamiento, para lo cual se busca detallar el concepto y naturaleza jurídica (1) y se examinan las consideraciones doctrinales y jurisprudenciales sobre su origen, requisitos, contenido y alcance (2). En la tercera parte se incluye una descripción general sobre la figura de la falta de conformidad, los elementos que la componen y efectos, a fin de precisar que esta puede incluir las situaciones que en el derecho privado colombiano están reguladas de forma dispersa y con efectos distintos para cada situación. Esto con el propósito de advertir la necesidad con que cuenta actualmente el derecho privado colombiano de 
adoptar un sistema unificado de remedios por incumplimiento, tendencia que ya recogieron instrumentos internacionales de la contratación $\mathrm{y}$ varias reformas nacionales. Finalmente se ingresan unas conclusiones.

\section{Defectos de calidad y cantidad observables al momento de la entrega}

En el Código de Comercio colombiano se consagra una figura paralela a la obligación de saneamiento por vicios ocultos, y es la relativa a la responsabilidad del vendedor por los defectos de calidad, identidad y cantidad observables al momento de la entrega de la cosa. En este punto se hará referencia a la naturaleza de dicha responsabilidad, además de su nexo con las acciones edilicias, previa indagación de la noción y alcance de lo que puede entenderse por "defectos observables".

\section{Concepto y alcance.}

Tratándose de vicios redhibitorios, han surgido dos conceptos en la doctrina: el funcional y el material (Verda De, 2009, pp. 24-33). Según este último, el defecto a calificarse como vicio redhibitorio, además de cumplir con los requisitos de ser anterior al contrato y oculto al menos para el comprador, afecta el uso normal de la cosa. Por el contrario, para la primera concepción el uso afectado puede ser tanto el normal como el pactado de forma expresa o tácita con el vendedor, lo cual además reduce el campo para eventuales diferenciaciones con el incumplimiento y la nulidad por error. En el derecho colombiano se asume la noción funcional. En materia civil, porque así lo considera la jurisprudencia y en materia comercial, porque lo dispone expresamente el artículo 934 del Código de Comercio (Oviedo, 2010, p. 249; Oviedo, 2012, pp. 98-103).

En cuanto se refiere a defectos observables a la entrega, así las normas no lo señalen, el concepto debe obedecer a una noción funcional, al tener cierta relevancia por no cumplir con las características esperadas por el comprador, además de comprometer el uso natural o pactado entre las partes para poder ser protestados por él, pues de lo contrario deben tolerarse ${ }^{2}$. Esta figura está consagrada en el artículo 939 del Código de Comercio colombiano, así:

Entregadas las mercaderías vendidas, el comprador no será oído sobre defectos de calidad o faltas de cantidad toda vez que las haya examinado al tiempo de la entrega y recibido sin previa protesta.

El vendedor tendrá derecho a exigir del comprador el inmediato reconocimiento o el recibo que acredite la entrega de la cosa a satisfacción, y si el comprador no hace reserva de su facultad de protestar o de examinar posteriormente la cosa, se estará a lo dispuesto en el inciso primero de este artículo.

A su vez, según el artículo 940 del Código de Comercio si al momento de la entrega el comprador alega que el bien no es de la especie o calidad convenida, o no ser de recibo, se aplicará el artículo 913 del Código. De hecho, esta norma dispone, en el inciso primero, otro supuesto fáctico a incluir en los analizados: si la venta se hace sobre muestras o sobre determinada calidad conocida en el comercio o determinada en el contrato, estará sujeta a la condición resolutoria si la cosa no se conforma a dicha muestra o calidad. Así entonces, conforme a estas disposiciones, el juez decidirá la eventual devolución o rebaja del precio y la indemnización de perjuicios por el incumplimiento ${ }^{3}$.

\section{Relación con las acciones por vicios ocultos y por incumplimiento.}

Estas normas no precisan si los defectos de calidad, identidad y cantidad a los que se refieren coinciden o no con los vicios ocultos. Por ello, se genera la inquietud consistente en determinar si el comprador que, habiendo recibido sin protestar por defectos de calidad o cantidad al momento de la entrega, puede después alegar 
la presencia de vicios ocultos para interponer la acción redhibitoria o de rebaja de precio o si por el contrario significa una renuncia de tales acciones. Tampoco es claro si estas acciones excluyen la posibilidad de interponer actos de resolución por inejecución o de ejecución forzosa de la prestación, al entenderse que el vendedor entregó una cosa diferente de la pactada y de esta manera se violó el principio de identidad e integridad del pago, ya mencionado.

Puede considerarse a estos vicios distintos de los redhibitorios, al poderse calificar como defectos aparentes y observables al tiempo de la entrega, pues los ocultos por el contrario, al tener tal requisito no pueden advertirse a simple vista al momento de la recepción y examen de los bienes, exigido por las normas mercantiles en alusión.

En Colombia, la doctrina no ha puesto mayor atención a la figura planteada, salvo en algunos trabajos recientes. Así, Cárdenas (2007) considera que si los defectos de calidad no pueden apreciarse al momento de la entrega, son ocultos y por tanto están sometidos a las reglas de vicios redhibitorios (p. 279). También Mantilla y Ternera (2008) afirman que lo establecido en el artículo 939 del Código de Comercio solo aplica para los vicios aparentes y no los ocultos (p. 320).

En este sentido se encuentra un fallo colombiano relativo a la demanda por incumplimiento interpuesta por un comprador de hierro alegando un faltante en la cantidad entregada, que aunque basado en el Código de Comercio de 1887, distinguió entre vicios aparentes y ocultos, de forma que frente al artículo 251 del Código anterior, consideró que ante los aparentes, no cabían reclamos posteriores si no se objetaban dentro de los tres días posteriores a la entrega, que era lo que disponía la norma (Marco A. Pico vs. Manuel Neira M., 1952, marzo 27).

De una forma similar se pronunció la Corte Suprema de Justicia en sentencia de septiembre de 1991 (Industria panificadora El Arbolito vs. Wetson, 1991, septiembre 11), en un caso relativo a la demanda de resolución de un contrato de venta de un horno industrial por incumplimiento del vendedor -pues dicho bien adolecía de un defecto que impedía su uso para el fin pactado entre las partes-. La corporación indicó que deben distinguirse vicios observables antes y otros después de la entrega, en cuyo caso caben alternativamente la redhibitoria o la de rebaja de precio, además de la garantía comercial de buen funcionamiento.

Por otra parte, existe un aspecto en el Código de Comercio colombiano que resulta poco claro. El artículo 931 de dicho estatuto determina que el comprador tendrá cuatro días posteriores a la entrega o dentro del plazo estipulado en el contrato, para alegar defectos de cantidad o calidad, controversia que se decidirá judicialmente con relación a si por los defectos de la cosa

[...] se afecta notablemente su calidad o la hacen desmerecer en forma tal que no sea de recibo o lo sea a un precio inferior. En este caso, el comprador tendrá derecho a la devolución del precio que haya pagado y el vendedor se hará de nuevo cargo de la cosa, sin perjuicio de la indemnización a que esté obligado por el incumplimiento ${ }^{4}$.

Cárdenas (2007) sugiere que hay una jerarquía cronológica, de manera que si el comprador " $[. .$.$] no examina las cosas, ni se le exige$ el reconocimiento de la cosa, o si hace reserva de su facultad de examinar la cosa posteriormente, será aplicable el artículo 931 [...]" (pp. 279-280; Mantilla \& Ternera, 2008, p. 322).

Resulta incoherente sostener que si el comprador no protestó o no hizo reserva de la facultad de examinar ulteriormente, cuente la posibilidad del artículo 931 del Código de Comercio de protestar dentro de los cuatro días siguientes a la entrega o dentro del plazo fijado en el contrato. El artículo 939 es perentorio al señalar que el comprador "no será oído" si recibió 
sin protesta alguna o si no se reservó la facultad de protestar. Por ello la forma propuesta de entender los artículos en comento es la siguiente: el comprador puede protestar al momento de la entrega o reservarse la facultad de examinar después el bien. A partir de esto, cuenta con cuatro días para alegar dicha falta de calidad o cantidad o el tiempo pactado, y así someter la diferencia a decisión judicial, para pedir se rebaje el precio o se resuelva el contrato según si por los defectos se afecta notablemente su calidad o bien proceda una rebaja de precio. Además, estos defectos de calidad no desplazan a las reglas sobre vicios redhibitorios, las que aplicarían para defectos ocultos y no aparentes al momento de la entrega, pero que de todos modos también permitirían al comprador interponer una acción redhibitoria o una de rebaja de precio.

Por otro lado, y en relación con la posibilidad para el comprador de acudir a las medidas generales por incumplimiento -y así mediante una acción de ejecución forzosa obligar al vendedor a entregar una cosa que cumpla con las especificaciones de cantidad, calidad y tipo pactadas en el contrato-, se encuentra la base para pronunciarse en pro de esta posibilidad en el hecho de considerar que las normas especiales que regulan la materia no establecen nada sobre el particular, lo que hace viable acudir a las reglas generales por incumplimiento, por lo que se trataría de un evento de concurrencia acumulativa de disposiciones, supuestos y consecuencias, dado que estas no se excluyen sino que se complementan (Larenz, 2010, pp. 262-263).

\section{La garantía de buen funcionamiento}

En este punto se hará referencia a la garantía de buen funcionamiento, pues según se verá, la norma que la consagra no es clara en cuanto a su contenido y alcance, para así tratar de verificar cuál es la obligación a que queda sometido el vendedor frente al comprador en virtud de ella, además de su vínculo con las acciones edilicias por vicios ocultos.

\section{Concepto y naturaleza jurídica.}

El artículo 932 del Código de Comercio promulga la garantía de buen funcionamiento, a semejanza del artículo 1512 del Código Civil italiano ${ }^{5}$. La norma dicta:

Si el vendedor garantiza por tiempo determinado el buen funcionamiento de la cosa vendida, el comprador deberá reclamar al vendedor por cualquier defecto de funcionamiento que se presente durante el término de la garantía, dentro de los treinta días siguientes a aquel en que lo haya descubierto, so pena de caducidad.

El vendedor deberá indemnizar los perjuicios causados por cualquier defecto de funcionamiento que sea reclamado oportunamente por el comprador.

La garantía sin determinación de plazo expirará al término de dos años, contados a partir de la fecha del contrato.

Además, el artículo 933 consagra una presunción de su inclusión en los contratos de venta, en aquellos casos en que la costumbre así lo determinare: "Se presumen vendidas con garantía las cosas que se acostumbra vender de ese modo" (Código de Comercio).

El legislador emplea la palabra "garantía", en el sentido de que el comprador asume un riesgo por un hecho eventual, que afecte la idoneidad del bien, al impedirla o disminuirla (Luminoso, 2009, p. 310). Ahora, así la norma no lo indique, se asume también en sentido funcional el concepto de defecto constitutivo del supuesto de la misma, como en los vicios redhibitorios, de modo que a causa de este se perjudique el funcionamiento normal o pactado entre las partes, aunque en este caso la ley no exige requisito alguno sobre la gravedad o no del defecto. Incluso, se considera que para que el comprador pueda exigir el contenido de la garantía, no necesita de probar la existencia de ningún defecto sino solamente que la cosa no funciona o no lo hace adecuadamente. 
Fabricio Mantilla (2013) estima que la perspectiva de esta garantía es funcional y destaca que a diferencia del supuesto constitutivo de vicios redhibitorios, en la garantía de buen funcionamiento no se demanda ninguna calificación de la disfunción, por lo que ante cualquier problema el comprador está facultado para reclamar (p. 99).

Las partes son libres de pactar en el contrato que la incluya, el término de duración de la garantía, siempre y cuando este se fije como lo expresa el artículo 932 del Código de Comercio. De lo contrario, si ellas no determinaren el lapso, la norma lo decreta supletivamente en dos años contados desde la fecha del contrato. Con independencia del plazo de duración de la garantía, la norma da derecho al comprador de reclamar al vendedor por el defecto dentro de los treinta días siguientes a aquel en que lo haya descubierto so pena de caducidad. Son entonces dos plazos los que se establecen en la norma: uno, el de duración de la garantía, el cual puede ser el que reglen las partes o supletivo de dos años y otro a favor del comprador para interpelar al vendedor por el mal funcionamiento del bien.

\section{Consideraciones doctrinales y ju- risprudenciales sobre su origen, re- quisitos, contenido y alcance.}

Esta garantía, a la que la doctrina le ha dedicado poco espacio salvo en épocas recientes, amerita varias consideraciones sobre su origen, contenido y alcance. Se indicarán en este punto las dudas que surgen en torno a ello y las posturas asumidas por la doctrina y la jurisprudencia.

La primera inquietud concierne a su origen. Así, mientras el artículo 932 del Código de Comercio sugiere que la garantía debe incluirse de forma expresa en el contrato, sin exigir que para ello deba observarse ninguna formalidad, siguiendo la regla general de consensualidad para la expresión de la voluntad establecida en el artículo 824 del mismo Código, la norma siguiente dispone que su génesis puede ser consuetudinario, y así en ese caso no se requerirá pacto que la incluya, pues se entenderá pactada ${ }^{6}$. Además, si se incorpora en la publicidad del vendedor, lo obliga, así no se haya estipulado en el contrato.

El fundamento para esta afirmación lo constituye el artículo 29 de la ley 1480 de 2011, según el cual las condiciones objetivas y específicas que se anuncian en la publicidad obligan al anunciante, en los términos de dicha publicidad. En el derecho italiano, se ha entendido que la garantía puede asumirla el vendedor en virtud de un pacto expreso, y puede estar contenida en la publicidad, en cualquier documento que acompañe la entrega de la mercancía o el envío de una confirmación de orden o factura (Greco \& Cottino, 1981, p. 368).

Estos aspectos llaman la atención de Cárdenas (2007), quien destaca el alcance relativo de la misma y afirma que no opera para todo tipo de compraventas mercantiles, sino tan solo en aquellas en que se hubiere pactado, o cuando la costumbre lo determinare (p. 255).

La segunda inquietud atañe a los requisitos para que proceda esta garantía. En efecto, la norma no establece claramente sobre qué tipo de bienes puede recaer, ni el supuesto de hecho a verificarse para que proceda y tampoco el contenido de ella, señalando simplemente que el vendedor deberá indemnizar los perjuicios causados por el defecto de funcionamiento reclamado de forma oportuna por el comprador.

Según asevera Cárdenas (2007) basándose en comentarios de la doctrina italiana, cubre cualquier cosa de duración y solo excluye los bienes consumibles, incluso pudiendo quedar incluidos los inmuebles (p. 255). Adicionalmente, dice el autor, a diferencia del requisito de gravedad exigido para los vicios ocultos, en la garantía de buen funcionamiento no es necesario que el defecto tenga tal ca- 
rácter (p. 258). En el derecho italiano, se comprende que la garantía de buen funcionamiento ampara al comprador independientemente de la causa que pudo haber impedido el resultado, sea que consista en una diferencia de tipo o de cualidad, o en un vicio. Además, prescinde del todo de la culpa del vendedor (Greco \& Cottino, 1981, p. 366).

La tercera inquietud tiene que ver con el alcance de la garantía. Cabe indagar si en virtud de ella el comprador solo puede pedir una indemnización, o si por el contrario -y sin perjuicio de esto- tiene licencia para pedir su reparación o sustitución, o si tales posibilidades las puede determinar el juez atendiendo al caso particular, como sucede en el derecho italiano (Luminoso, 2009, p. 308). Rodríguez (2009), al comentar esta figura declara que la acción de ella derivada no da lugar ni a la rebaja del precio ni a la resolución del contrato y que solo abarca un derecho indemnizatorio (p. 135).

Por su parte Cárdenas (2007), apoyado en sentencia de 11 de septiembre de 1991, admite la posibilidad de reparación (Mantilla \& Ternera, 2008, p. 314). En efecto, la Corte Suprema de Justicia en esa sentencia, en dos apartados afirma la posibilidad de reparación, aunque en uno de ellos pareciera entender que la garantía de buen funcionamiento incluye por sí misma la reparación y la indemnización de perjuicios; mientras en otro sugiere que dicha reparación tiene cabida si el vendedor se obligare en virtud de ella, estableciendo además que no comprende por sí sola la resolución del contrato. Así lo manifestó el fallo en los apartados en mención:

De suerte que, si la garantía por mal funcionamiento comprende solo la acción reparatoria e indemnizatoria, cuando el comprador demanda la resolución del contrato en consideración a que el vicio de la cosa que recibió no le permite destinarla al uso para el cual fue adquirida, lo que está ejercitando es la acción consagrada en el artículo 934 del C. de Co., y no la prevista por el artículo 932 que, como se dijo, solo comprende un derecho indemnizatorio por defecto de funcionamiento (Industria panificadora El Arbolito vs. Wetson, 1991, septiembre 11).

En el otro aparte de las consideraciones, dijo la Corte:

Además, como el vendedor que otorga la garantía de buen funcionamiento se obliga, generalmente, a reparar y a indemnizar los perjuicios causados por el vicio, es del caso concluir que el artículo 932 del C. de Co., no otorga al comprador acción resolutoria per se ni tampoco en concordancia con el artículo 870 ibídem aun en el evento en que el vendedor incumpla con la aludida obligación de garantía, porque de ser así cualquier defecto de funcionamiento, por insignificante que fuera, daría lugar a este resultado, con notorio quebranto de la seguridad y estabilidad que debe reinar en los negocios mercantiles. Otra cosa es que, por ser el vicio de mayor entidad, tal como acontece cuando hace impropia la cosa para su natural destinación o no permite utilizarla en el fin previsto al adquirirla, este genere la resolución contractual, porque en este supuesto se está ya frente a la situación del artículo 934 del C. de Co., que sí da cabida y amerita el ejercicio de la acción resolutoria (Industria panificadora El Arbolito vs. Wetson, 1991, septiembre 11).

La cuarta inquietud es la referente a su compatibilidad o no con la obligación de saneamiento por vicios ocultos, dado que los artículos en alusión nada ordenan sobre el particular. Desde la perspectiva italiana, Luminoso (2009) sostiene que aunque es una postura corriente asumir que la cláusula sobre la garantía de buen funcionamiento refuerza la posición del comprador, por el modo en que se formula en la práctica, reduce de forma notoria la tutela del comprador limitándole el derecho a la sola reparación de la cosa y excluyendo la garantía ordinaria por los vicios (p. 309). Savanna (2007), en opinión diferente 
y apoyándose además en fallos pronunciados en este sentido, expresa que esta garantía refuerza la tutela del comprador y opera en vía autónoma e independiente respecto de la garantía por vicios ocultos y la responsabilidad por falta de calidad. Se distingue, afirma, de la garantía ordinaria por su menor complejidad en la reglamentación, siendo tan solo necesario que el comprador pruebe la falla, ante lo cual el vendedor responderá por el solo hecho de que se verifique el defectuoso funcionamiento del bien (pp. 95-97).

En el derecho colombiano, Bonivento (2012) parece sugerir que se trata de una garantía adicional a la obligación de saneamiento por vicios redhibitorios cuando dice: "Se establece, así mismo, una garantía convencional por cualquier defecto de funcionamiento" (p. 154).

La facultad de acudir a las diferentes acciones, a escogencia del comprador, también la asumió la Corte Suprema en la sentencia citada de 1991, al evidenciar que tratándose de una compraventa mercantil y al producir el hecho constitutivo del vicio una falla en el funcionamiento, el comprador podría acudir ya sea a la acción del artículo 932 del Código de Comercio relativa a la garantía de buen funcionamiento, o a las acciones del artículo 934 del mismo Código sobre vicios ocultos. Así lo precisó la Corte en la parte correspondiente del fallo:

Estos últimos, vale decir, los que se observan después de recibida la cosa, cuando están amparados por dicha garantía, convencional o presunta (artículo 933 del C. de Co.), deberán reclamarse en las oportunidades indicadas en el artículo 932 del Código de Comercio; no obstante, si así no lo hiciere el comprador y el vicio es de la naturaleza prevista en el artículo 934 ejusdem, podrá también este ejercitar alternativamente las acciones que esta norma indica, es decir, la redhibitoria o la cuanti mínoris, en ambos casos con indemnización de perjuicios, y por el procedimiento ordinario (arts. 396 y 397 del Código de Procedimiento Civil).
La posibilidad de acumulación con las acciones edilicias ya la había admitido la Corte Suprema en sentencia de 23 de julio de 1986 (M. R. Inversiones vs. Cooperativa Agropecuaria del Meta), en la cual adujo que el comprador puede optar tanto por las acciones redhibitoria o de rebaja de precio, como por las especiales, en este caso la garantía de buen funcionamiento. En este fallo la Corte consideró que al menos en la legislación mercantil, se consagra una gama de posibilidades ante la presencia de defectos del bien que no se excluyen unas con otras, sino que son recursos a los cuales puede acudir el comprador, optando entre el más conveniente.

Los hechos del caso fueron los siguientes: se celebró un contrato de compraventa de semilla de arroz certificada "Metica I". La vendedora demandó incumplimiento del pago del precio junto con la correspondiente declaratoria y ejecución, además de indemnización de perjuicios. La demandada propuso la excepción de contrato no cumplido al asumir como una de las principales obligaciones del vendedor en el contrato de compraventa, la de entregar la cosa en el lugar convenido sin vicios o defectos que la hagan impropia para su natural destinación o para el fin previsto en el contrato, puesto que la semilla enajenada tenía problemas de germinación, solamente detectables previo análisis técnico especializado.

El juzgado de primera instancia declaró no probadas las excepciones propuestas y condenó al pago de las sumas de dinero correspondientes. La demandada apeló la sentencia impugnada y el Tribunal Superior de Villavicencio la confirmó en todas sus partes. Contra este fallo se interpuso recurso de casación por aplicación indebida y falta de aplicación de algunos artículos del Código de Comercio; el Código Civil y el Código de Procedimiento Civil, además de error de hecho por falta de apreciación de las pruebas. La Corte casó la sentencia del tribunal, revocó algunos de sus apartes y confirmó otros. En las consideraciones la Corte indicó que en caso en que la cosa no sirva para su uso normal o solo sirva imperfectamente, 
[...] el Código Civil estatuye la acción redhibitoria y la acción estimatoria o de rebaja de precio (artículo 1917 reiterado en el Código de Comercio en el artículo 934). Empero el ordenamiento mercantil va más allá en lo atinente a esas modalidades de garantía de la cosa en cuanto permite discutir, por los trámites de un procedimiento verbal sobre la calidad, cantidad y sanidad (artículos 914, 915, 916, 931, 939), o sobre el funcionamiento (artículo 934). Frente a esa amplia gama de remedios legales, puede moverse el comprador para optar por la que más convenga a sus intereses o propósitos (M. R. Inversiones vs. Cooperativa Agropecuaria del Meta, 1986, julio 23).

A continuación se hará referencia a las inquietudes sugeridas en los párrafos precedentes, señalando la opinión que amerita cada una de ellas. En cuanto al tipo de bienes susceptibles de ser amparados con la garantía de buen funcionamiento, a diferencia de la opinión que la limita a las cosas no consumibles, también las consumibles, puede afirmarse, podrían estar cubiertas con ella si durante su utilización se verifica un defecto que incide en la utilidad esperada de las mismas. Al no hacer la norma distinciones de ningún tipo, puede recaer sobre cualquier tipo de bien objeto de una venta mercantil.

Además, al soportarse en el sentido literal de las palabras, se puede decir que esta garantía procede cuando la cosa tiene una falla que afecta su uso o funcionamiento. Aunque de todas formas, se considera que debe tratarse de un defecto que comprometa de alguna manera el funcionamiento del bien para que la garantía pueda operar, y por consiguiente, en la garantía de buen funcionamiento, caben tanto los defectos graves como los leves que alteren el funcionamiento de la cosa objeto del contrato. Alpa (2004) ha destacado ya en el derecho italiano, que la garantía de buen funcionamiento es válida no solo en casos de defectos graves sino también mínimos que impidan el uso de la cosa y que por ello impliquen la responsabilidad del vendedor (p. 256).
Ahora, en lo que respecta a su alcance, aunque la norma parece sugerir que comprende únicamente un derecho indemnizatorio en caso de verificarse un defecto de funcionamiento del bien y no menciona la reparación, la figura no parece excluirla y a ella podría llegarse asumiendo que una forma de indemnizar al comprador, es mediante la reparación de la cosa o porque al pactar la garantía se hubiere incluido tal posibilidad.

De todas maneras, se considera, la reparación podría obtenerse en virtud no solo de la garantía misma, sino también de la acción genérica de ejecución forzosa por incumplimiento, cuyo origen legal da mayor seguridad al comprador ante la incertidumbre de si la costumbre la admite o si al haberse incorporado al contrato, incluye o no dicha reparación.

Con todo, no queda claro si se admite o no la sustitución de la cosa en virtud de esta garantía. Sobre el particular puede destacarse que ni las interpretaciones doctrinales ni la jurisprudencia, aceptan la sustitución del bien en caso de mal funcionamiento. No se debe descartar esta posibilidad, pues dentro de la indemnización a que tiene derecho el comprador, puede tener cabida decretar la entrega de un bien que funcione. Aunque es más seguro para el comprador acudir a la acción genérica de ejecución forzosa por incumplimiento de la obligación de calidad o idoneidad, para así obtener también la entrega de la cosa prometida y que esta cumpla con las condiciones presupuestadas en el contrato, lo que llevaría al vendedor a ser compelido a entregar una cosa que funcione, en lugar de una que no lo hace o lo hace imperfectamente.

Se puede entender también que la acción derivada de la garantía de buen funcionamiento no por especial excluye la aplicación de aquella y lo que en esta no se encuentre expresamente regulado, se pueda interponer la acción redhibitoria o la de rebaja de precio. En este sentido, si se asume a la garantía de 
buen funcionamiento basada en un defecto que impide el uso del bien, concurrente además con los requisitos de ser oculto y grave, constituye un vicio redhibitorio y al no contener la garantía de buen funcionamiento una acción redhibitoria o una de rebaja de precio, cabe acudir a las normas que las regulan para aplicarlas.

Se considera además, aplicando por analogía el artículo 931 del Código de Comercio ya referido relativo a las objeciones del comprador por falta de calidad, que en cada caso concreto deberá valorarse el defecto de funcionamiento y por ello, parafraseando la norma, se puede decir que se deberá determinar si,

[...] los defectos de la cosa afectan notablemente su calidad o la hacen desmerecer en forma tal que no sea de recibo o lo sea a un precio inferior. En este caso, el comprador tendrá derecho a la devolución del precio que haya pagado y el vendedor se hará de nuevo cargo de la cosa, sin perjuicio de la indemnización a que esté obligado por el incumplimiento.

Lo mismo se obtendría en aplicación del artículo 1925 del Código Civil, el cual frente a vicios que no se califiquen como graves, permite la acción de rebaja de precio. El empleo de esta norma tiene cabida en materia mercantil, no solo por analogía, sino además por la remisión directa que a las reglas civiles sobre obligaciones y contratos hace el artículo 822 del Código de Comercio ${ }^{7}$.

También se debe destacar que, a diferencia de las acciones edilicias donde la indemnización de perjuicios tiene lugar cuando se establece el dolo o mala fe del vendedor en los casos en que conocía los vicios y no los declaró o debía conocerlos, la garantía de buen funcionamiento no requiere prueba de tal situación, apuntando el artículo 932 del Código de Comercio únicamente que el comprador tendrá derecho a una indemnización por cualquier defecto de funcionamiento reclamados de forma oportuna. Por ello se repara en que se trata de una indemnización objetiva de carácter contractual ante el incumplimiento de la mencionada garantía, regida por las reglas de derecho común.

Según Mantilla (2013) se trata de perjuicios ocasionados "en la cosa", por lo cual la indemnización solo cubriría el daño emergente (p. 109). Al contrario de esta opinión, se considera que abarca tanto el daño emergente como el lucro cesante ocasionados por el defecto de funcionamiento, pues la norma así lo dispone sin hacer distinciones: "El vendedor deberá indemnizar los perjuicios causados por cualquier defecto de funcionamiento que sean reclamados oportunamente por el comprador" (también en Italia: Luminoso, 2009, pp. 310-311).

Además, y aunque es un tema sobre el que no hay mayores referencias en la doctrina y ninguna en la jurisprudencia, el plazo de dos años al que alude el artículo 932 a cuyo vencimiento expira la garantía, no es un término al que se someta la acción de indemnización de perjuicios. La forma, como se cree, debe entenderse el mencionado precepto legal, es que durante el término convencional o supletivo legal de dos años, el comprador está amparado por el vendedor frente al buen funcionamiento de la cosa, lo cual genera que si durante ese tiempo apareciere un defecto que comprometiere el funcionamiento, el comprador podrá exigir la reparación y eventual sustitución. Ello, con independencia del derecho a obtener una indemnización por los daños producidos con ocasión del defecto, acción que al no tener un término prescriptivo especial, se someterá a las reglas del derecho común, esto es: diez años (Cárdenas, 2007).

Finalmente, esta garantía es innecesaria, pues no se ve que mejore la posición del comprador frente a las acciones edilicias o las acciones por defectos de calidad mencionadas; redundante, pues el defecto que afecte el buen funcionamiento coincide con el vicio en sentido funcional y puede además suscitar dificultades interpretativas en relación con la inclusión o no 
en el contrato cuando las partes no la hubieran pactado, debiendo probar la existencia de una costumbre que la admitiera.

Ahora bien, por su naturaleza no resulta del todo claro si significa exclusión o no de las acciones edilicias y de las acciones generales por incumplimiento o error. Incluso, el poder ser incorporada por pacto expreso al contrato, no varía en nada la posibilidad ya existente en la garantía edilicia de poder las partes incluir cláusulas por las cuales hagan redhibitorios vicios que por su naturaleza no lo son o en uno y otro caso puedan ampliar el contenido de la garantía, pactando por ejemplo la reparación o sustitución.

\section{La falta de conformidad}

Como se expresó en la introducción, la propuesta de este artículo consiste en sugerir que al derecho colombiano le convendría, ya sea una modificación de las reglas civiles y comerciales que regulan de modo fraccionado los eventos de cumplimiento defectuoso de las obligaciones, o bien una reinterpretación de las normas vigentes en clave de la manera como instrumentos internacionales han reglamentado situaciones como las descritas. Máxime, cuando uno de ellos: la Convención de las Naciones Unidas sobre los Contratos de Compraventa Internacional de Mercaderías forma parte del derecho colombiano, toda vez que se acogió en la ley 518 de 1999.

Valga reiterar que el objetivo de este artículo no es analizar de modo exhaustivo la figura de la falta de conformidad, lo que se hará en un trabajo posterior, sino poner de presente, previa una descripción general de la misma, las ventajas con que cuenta frente al sistema nacional descrito en párrafos anteriores.

\section{La obligación de conformidad.}

Dimana de lo establecido en la Convención sobre compraventa, que el vendedor además de entregar materialmente la cosa, trans- ferir su dominio y conceder los documentos relacionados, según disposición del artículo 30 , debe proporcionar mercancías cuya cantidad, calidad y tipo correspondan a lo estipulado en el contrato, lo que también incluye el envase y embalaje. La infracción de esta obligación significa incumplimiento del contrato y da lugar a los remedios para ello consagrados en tal Convención, los que dicho sea de paso, obedecen a un sistema unitario que abarca el no cumplimiento, el cumplimiento tardío y el cumplimiento defectuoso de las prestaciones contractuales (Díez-Picazo et al., 2002, p. 324; Morales, 2012, pp. 18-19).

La falta de conformidad regulada en el artículo 35 de la Convención no solo se sujeta a un concepto material, sino también funcional. Esto se deriva de lo dispuesto en los numerales 1 y 2 del mismo artículo, según el cual para que se cumpla la obligación de conformidad, la cantidad, calidad, tipo, envase y embalaje de los bienes deben corresponder a lo estipulado en el contrato, pero también que sean aptos para los usos a los cuales ordinariamente se destinen mercancías de igual tipo; resulten idóneos para cualquier uso especial convenido expresa o tácitamente; posean las cualidades de la muestra o modelo que el vendedor haya presentado al comprador y que estén envasados o embalados en la forma habitual para tales mercaderías o en la adecuada para conservarlos y protegerlos (Morales, 1998, p. 294; Schwenzer, 2010, p. 571).

Como puede advertirse, la falta de conformidad abarca las situaciones que en los códigos de tradición europea continental corresponden a los vicios redhibitorios. Igualmente, comprende las circunstancias que se analizan en este trabajo, reguladas en el Código de Comercio colombiano, pues al no distinguir en si los defectos que generan la falta de conformidad son observables u ocultos, se debe entender que engloba ambos. También alcanza a la entrega de una cosa distinta a la pactada (Fenoy, 1996, p. 365; Martín, 2010, p. 22; Navas, 2004, p. 148). 
En cuanto a la gravedad o no de los defectos que significan falta de conformidad, puede entenderse que no por el hecho de no mencionarse en la norma, quiere decir que esta la desconozca. Por el contrario, si se parte del supuesto de distinguir entre incumplimiento simple y esencial -entendido este en los términos del artículo 25 como el causante de un perjuicio tal a la otra parte que la prive sustancialmente de lo que tenía derecho a esperar en virtud del contrato-, puede señalarse que la gravedad de la falta de conformidad es un elemento determinante para calificar o no al incumplimiento del vendedor como esencial y por ende, fijar el tipo de remedio de que dispone el comprador.

\section{EI sistema unificado de remedios.}

Como se anunció, la falta de conformidad está tratada en la Convención como un supuesto de incumplimiento. Ante ello, el comprador dispone del abanico de posibilidades que incluye acciones que en los sistemas de tradición europea continental pertenecen al saneamiento por vicios ocultos y también aquellas pertenecientes al sistema general de acciones por incumplimiento contractual (Ghestin, 1983, pp. 219-220), el cual se pasa a describir de forma resumida.

Una de ellas es que el comprador pueda pedir la reparación o subsanación de la falta de conformidad, según el artículo 46 núm. 3. La sustitución de la mercadería, posibilidad consagrada en el núm. 2 de dicho artículo, procede solamente cuando el incumplimiento fuere esencial, lo cual según se apuntó, procederá cuando la falta de conformidad sea de cierta magnitud.

La resolución del contrato por incumplimiento, que en los términos ya anotados del artículo 25 solo procede cuando el incumplimiento sea esencial, se corrobora en el artículo 49 numeral 1 literal a.

La rebaja de precio, también está dentro de la gama de posibilidades para el comprador, lo que se hará en proporción a la diferencia existente entre el valor que las mercancías efectivamente entregadas tenían en el momento de la entrega y el que habrían tenido en ese momento bienes conformes.

Por último, la indemnización de daños para el perjudicado por el incumplimiento del contrato regulada en el artículo 74 de la Convención, no se limita a eventos en que el vendedor conocía o debía conocer y no declaró, como sí al derecho nacional.

Como ya se vio, se extraña en el derecho nacional la posibilidad de obtener, según el sistema de protección edilicio y las reglas sobre defectos de calidad y garantía de buen funcionamiento, la sustitución o reparación de los bienes, pese a que una de las propuestas de este trabajo consiste en integrar el que se considera es un vacío de las reglas especiales, con lo estipulado en las normas generales. Se puede señalar como otra solución, la de aplicar por analogía las regulaciones descritas en la Convención de las Naciones Unidas sobre los Contratos de Compraventa Internacional de Mercaderías, para integrar las normas internas.

En la doctrina desde tiempo atrás se hallan voces que se pronuncian a favor de esta posición (Illescas \& Perales, 2003, pp. 111113). Así por ejemplo, Perales (1996) expone la posibilidad de acudir a la Convención en casos nacionales para efectos de llenar varios vacíos o suplir inconsistencias de las normas españolas, civiles y comerciales, relacionadas con diversos aspectos de la formación del contrato (pp. 124-132). Esta postura también la asume en Colombia Cárdenas (2003), quien se ha referido sobre la probable aplicación de este instrumento a casos domésticos.

Adviértase que esta posibilidad ha sido asumida por algunas decisiones de tribunales de diferentes países en casos surgidos a partir de contratos de compraventa nacionales. La tendencia que se observa en algunos de aque- 
llos fallos, ha sido precisamente la de haber aplicado por analogía la Convención y en otros, el haberla mencionado para sustentar los argumentos.

En Italia así se sentencia, a pesar de no haberunaposiciónuniforme en lajurisprudencia. En sentido positivo, se encuentra un fallo del tribunal de Nápoles, que la aplicó por analogía a un caso nacional (Tribunale Napoli, 29 de marzo de 2001, citado por Torsello, 2008, p. 200), aunque en un caso posterior, la Corte de Casación rechazó esa posibilidad (Corte di Cassazione, 28 de noviembre de 2003, n. 18229, citado por Torsello, 2008, p. 200). De todas formas, la misma Corte, en otra sentencia sí aceptó la posibilidad de usarla como referencia (Corte di Cassazione, 16 de noviembre de 2007, n. 23794, citado por Torsello, 2008, p. 200).

En España existen decisiones judiciales en igual sentido: por ejemplo, un fallo del Tribunal Supremo de 2006, que aplicó la Convención a un contrato de venta de una vivienda. El pleito se inició a propósito de la decisión de los compradores de resolver el contrato, pidiendo que se les restituyera el precio por incumplimiento de los vendedores, dado que al momento de celebración del contrato los vendedores sabía de los derechos de terceros que recaían sobre la misma vivienda, consistentes en una anotación preventiva de demanda "[...] para obtener la elevación a escritura pública de un invocado contrato de compraventa verbal concertado con los vendedores" (Casimiro y María Milagros vs. Almudena y Tomás, 2006, octubre 31); quienes de hecho demandaron para reclamarlos. Las decisiones de instancia, y también el Tribunal Supremo, dieron la razón a los compradores, aduciendo "[...] que la existencia de una demanda tendiente a obtener el reconocimiento de la eficacia de un previo contrato de compraventa y su elevación a público supone un incumplimiento del contrato de compraventa $[\ldots]$ ", pues los vendedores conocían la existencia de otras personas detentadoras de la condición de compradores.
El tribunal asumió que en el derecho español tiene aplicación el concepto de incumplimiento esencial del artículo 25 de la Convención de las Naciones Unidas sobre los Contratos de Compraventa Internacional de Mercaderías, para entenderlo como una situación constitutiva de violación sustancial del contrato que produce la insatisfacción de las expectativas del otro contratante. De esta forma, señaló que al ser la Convención parte del régimen legal interno, sus disposiciones resultan útiles para interpretar el derecho nacional conforme a la realidad social al momento de aplicarlo. Así lo dijo el fallo:

El criterio recogido en una disposición internacional de carácter convencional que forma parte de nuestro ordenamiento jurídico $\mathrm{y}$ reflejado también en un documento en que se formulan jurídicamente los principios que integran la llamada lex mercatoria [ley comercial] comunes a los distintos ordenamientos, en cuanto reflejan y pretende ordenar, con el propósito de elaborar normas uniformes, la práctica seguida en relaciones comerciales que superan el ámbito estatal, debe servirnos para integrar el artículo 1124 CC (LEG 1889, 27) siguiendo el mandato de interpretarlo con arreglo a la realidad social del momento en que se aplica (Casimiro y María Milagros vs. Almudena y Tomás, 2006, octubre 31).

Baste insistir sobre esta posibilidad haciendo referencia a una sentencia colombiana donde la Corte Suprema de Justicia acogió ya esta posición, dictada gracias a un caso a propósito del cual se decidió acudir a la figura de la mitigación de daños consagrada en el artículo 77 de la Convención de las Naciones Unidas sobre los Contratos de Compraventa Internacional de Mercaderías, por lo que es de destacar que la postura aquí asumida halla en Colombia no solo sustento doctrinal, sino también jurisprudencial. Por la relevancia del fallo en el derecho colombiano, se incluye enseguida un resumen del mismo.

La Sociedad Marítimas Internacionales Ltda., celebró un contrato de transporte de 
1.015,97 toneladas de fosfato bicálcico con Distribuidora Petrofert Ltda., para ser entregadas a la Caja de Crédito Agrario, Industrial y Minero (para efectos de esta referencia, la Caja Agraria). Según lo pactado, el transporte se realizaría por vía marítima a cargo de otra sociedad colombiana. La nave llegó al puerto de Barranquilla a las 15:40 horas del 27 de noviembre de 1982 a la espera de poder atracar en los muelles de la terminal para lo que se necesitaba que previamente el destinatario cancelara los fletes respectivos.

Transcurrieron cinco meses sin que la demandante pudiera descargar las mercancías, por lo que el 25 de marzo de 1983 inició la acción correspondiente para descargar y obtener la orden de remate y de esta forma, contar con los recursos para el pago de fletes y demás gastos ocasionados. Ante ello, se demandó a la Caja Agraria y Almagrario (que era el agente aduanero de la Caja Agraria), además de la Distribuidora Petrofert Ltda., por los daños causados. El juzgado de conocimiento decidió en fallo de 3 de septiembre de 1996, negar las pretensiones de la demanda basado en que no estaba probada la culpa de las demandadas.

El Tribunal Superior del Distrito Judicial de Antioquia confirmó el fallo de primera instancia en relación con la Caja Agraria, al considerar que no se había probado una conducta dolosa o culposa de esta última, pues entre las partes del contrato se había pactado la apertura de una carta de crédito con un banco corresponsal extranjero que estaba destinado al pago de los fletes generados por el transporte del fosfato bicálcico. No obstante, condenó a Distribuidora Petrofert Ltda., al pago de los fletes respectivos.

La sociedad demandante interpuso recurso de casación para que se extendiera la condena a la Caja Agraria. La Corte en sus consideraciones, analizó la conducta que le correspondía a la empresa transportadora y entre otras razones, precisó el deber asumido por la víctima del daño en orden a mitigarlo, tomando como ejemplo de su inserción el derecho colombiano por medio del artículo 1074 del Código de Comercio y el artículo 77 de la Convención de las Naciones Unidas sobre los Contratos de Compraventa Internacional de Mercaderías, incorporada al ordenamiento nacional mediante ley 518 de 1999 y sobre este soporte concluyó, sin casar la sentencia (Sociedad Marítimas Internacionales Ltda. vs. Caja de Crédito Agrario, Industrial y Minero, Almacenes Generales de Depósito de la Caja Agraria, Instituto de Mercadeo Agropecuario, Banco Ganadero -Almagrario S. A.- y Distribuidora Petrofert Ltda., 2010, diciembre 16).

\section{Conclusiones}

Como principales conclusiones derivadas de este trabajo, además de las puntualmente señaladas, pueden destacarse las siguientes:

1. El Código de Comercio regula de forma paralela al sistema de protección edilicio, los defectos de calidad, cantidad y tipo observables al momento de la entrega del bien. Este concepto de falta de calidad observable a la entrega, también se debe mirar desde la óptica funcional, por lo que se refiere a defectos que comprometen el uso normal o convenido, que aunque sin requerir la gravedad de los vicios ocultos, deben comprometer el uso de alguna manera, pues de lo contrario serían defectos menores que debe tolerar el comprador.

2. Esto resulta compatible con las acciones edilicias y el hecho de que el comprador no haya protestado por los defectos observables al momento de la entrega, no lo priva de la posibilidad de acceder a las acciones por vicios ocultos, siempre y cuando sus requisitos se puedan verificar, pues se trata de supuestos diferentes.

3. La garantía de buen funcionamiento, que se puede pactar en el contrato o entender contenida en él si la costumbre lo determina, parte también de un supuesto de defecto de carácter funcional, aunque el comprador no requiere probar nada distinto a que la cosa no funciona, para ejercerla. 
4. La garantía de buen funcionamiento, a pesar de la falta de claridad normativa sobre su alcance, permite al comprador obtener mediante una acción de ejecución forzada, la reparación del bien o la sustitución, lo cual al no regularse en la disposición que la contiene, hace viable acudir a las acciones genéricas por incumplimiento.

5. Si la falla de funcionamiento cumple con los requisitos para ser calificada como vicio redhibitorio, permite al comprador interponer la acción redhibitoria o de rebaja de precio, posibilidades que al no estar consagradas en la ley que la regula, se rigen por las generales, por ser compatibles y no excluyentes.

6. La Convención de las Naciones Unidas sobre los Contratos de Compraventa Internacional de Mercaderías, determina un sistema unificado de supuestos por incumplimiento y de remedios para el acreedor afectado. Esto incluye la falta de conformidad que agrupa los supuestos dispersos del derecho nacional, y a diferencia de él dota al comprador de un sistema uniforme de remedios que se construye a partir de la calificación del incumplimiento en simple y esencial, y dota al comprador de la posibilidad de pedir la reparación o sustitución, la resolución del contrato, la rebaja del precio y/o una indemnización de perjuicios. La consagración de un sistema unificado de remedios como el descrito, evitaría problemas interpretativos y de aplicación de las normas nacionales, por lo que conviene pensar en una reforma legislativa o bien una interpretación de las normas nacionales que recojan los conceptos modernos que se imponen en el mundo a partir de la adopción de instrumentos internacionales como la Convención.

\section{Notas}

${ }^{1}$ Son conocidos los intentos en la jurisprudencia de algunos países como España e Italia, de dar al comprador mayores alternativas que la acción redhibitoria y la de rebaja de precio, para lo cual se ha estructurado la teoría del aliud pro alio, según la cual cuando la disconformidad en- tre lo pactado y lo entregado es tal, que supone la entrega de una cosa distinta y como tal, incumplimiento del vendedor (Agostinis, 2012, p. 21; Broseta \& Martínez, 2012, pp. 74-75; Fadda, 2005, p. 605; Gabrielli, 1987, pp. 1-13; Lombardi, 2010, p. 319; Orti, 1987, pp. 54-55; Prats, 1992, p. 5094; Rodríguez-Rosado, 2013, p. 178).

${ }^{2}$ En el artículo $5^{\circ}$ núm. $1^{\circ}$ de la ley 1480 de 2011, la calidad se define como la "Condición en que un producto cumple con las características inherentes y las atribuidas por la información que se suministre sobre él”.

3 Tanto en el Código de Procedimiento Civil (decreto 2282 de 1989, reformatorio del Código de Procedimiento Civil, art. 435 par. 1 núm. 8), como en el Nuevo Código General del Proceso (ley 1564 de 2012, art. 390 núm. 4), el tema se decide por proceso verbal sumario.

${ }^{4}$ La solución es similar a la que instaura el artículo 913 al que a su vez remite el artículo 940 del Código de Comercio.

${ }^{5}$ Guido Alpa (2004) relata que la garantía de buen funcionamiento fue introducida como una novedad al Código Civil italiano de 1942, dando uniformidad a prácticas convencionales que eran usuales en ciertos sectores, la que se considera como un tertium genus frente a la redhibitoria y la estimatoria (p. 253). El artículo 1512 del Código Civil italiano, que la consagra, establece: "Si el vendedor ha garantizado por un tiempo determinado el buen funcionamiento de la cosa vendida, el comprador, salvo pacto en contrario, debe denunciar al vendedor el defecto de funcionamiento dentro de los treinta días a contar del descubrimiento, bajo pena de decadencia. La acción prescribe a los seis meses a contar desde el descubrimiento. El juez, según las circunstancias, puede señalar al vendedor un término para sustituir o reparar la cosa en modo que asegure un buen funcionamiento, salvo el resarcimiento de los daños. Quedan a salvo los usos que establezcan que la garantía del buen funcionamiento se debe también en defecto de pacto expreso" (Messineo, 1979, p. 293). 
${ }^{6} \mathrm{Al}$ consultar acerca de la existencia de costumbres certificadas respecto a la garantía de buen funcionamiento, hallamos una en relación con el licenciamiento de software, pero no estrictamente con su venta, ejecutada por la Cámara de Comercio de Bogotá: "La garantía de buen funcionamiento en los contratos de licenciamiento de software: en Bogotá D. C., es costumbre mercantil que en los contratos de licenciamiento de software, se otorgue al cliente una garantía de buen funcionamiento del software por un término de un (1) año" (Cámara de Comercio de Bogotá, s.f.).

${ }^{7}$ El primer párrafo de este artículo reza: "Los principios que gobiernan la formación de los actos y contratos y las obligaciones de derecho civil, sus efectos, interpretación, modo de extinguirse, anularse o rescindirse, serán aplicables a las obligaciones y negocios jurídicos mercantiles, a menos que la ley establezca otra cosa".

\section{Referencias}

Abeliuk, R. (2008). Las obligaciones (Tomo 2, $5^{\mathrm{a}}$ ed.). Santiago: Editorial Jurídica de Chile.

Agostinis, B. (2012). La garanzia per i villi della cosa venduta. Le obligazioni del compratore. Artt. 1490 - 1499. En F. D. Busnelli (Dir.), Il Codice Civile, Commentario, fondato da Piero Schlesinger (pp. 3-251). Milano: Giuffrè.

Aguayo, J. (2011). Las manifestaciones y garantías en el Derecho de contratos español. Pamplona: Civitas, Thomson Reuters.

Alpa, G. (2004). Derecho del consumidor (Trad. N. Carreteros-Torres). Lima: Gaceta Jurídica.

Ángel De, R. (2013). Derecho de obligaciones en Europa. Algunos rasgos de la evolución en las dos últimas décadas. Barcelona: Bosch.

Bonivento, J. (2012). Los principales contratos civiles y su paralelo con los comerciales
(18 ed.). Bogotá: Librería ediciones del profesional Ldta.

Broseta, M., \& Martínez, F. (2012). Manual de Derecho Mercantil (Vol. 2, 19ª ed.). Madrid: Tecnos.

Cámara de Comercio de Bogotá. (s.f.). Licenciamiento de software. Recuperado http:// camara.ccb.org.co

Caprile, B. (2008). Las acciones del comprador insatisfecho: el cúmulo actual (ley de protección al consumidor, vicios redhibitorios, error sustancial, resolución por incumplimiento) y la tendencia al deber de conformidad en el Derecho Comparado. En F. Mantilla \& C. Pizarro (Coords.), Estudios de Derecho Privado en homenaje a Christian Larroumet (pp. 561-602). Bogotá: Fundación Fernando Fueyo; Universidad Diego Portales; Universidad del Rosario.

Cárdenas, J. (2003). La Convención de Viena y el Derecho Privado colombiano. En L. Diez-Picazo \& P. León De (Dirs.), Compraventa internacional de mercaderías. Comentarios a la Convención de Viena de 1980 (pp. 315-347). Bogotá: Pontificia Universidad Javeriana.

Cárdenas, J. (2007). La resolución por problemas de funcionamiento de la cosa en el derecho colombiano: el régimen interno vicios ocultos y garantía mínima presunta $-\mathrm{y}$ el régimen de la compraventa internacional de mercaderías. En J. Gaitán \& F. Mantilla (Dirs.), La terminación del contrato. Nuevas tendencias del Derecho comparado (pp. 217-316). Bogotá: Universidad del Rosario.

Carrasco, A. (2010). Derecho de contratos. Cizur Menor: Aranzadi-Thomson Reuters.

Decocq, G., Grimaldi, C., Huet, J., \& Lécuyer, H. (2012). Les principaux contrats spéciaux. Paris: LGDJ. 
Decreto 410 de 1971. Por el cual se expide el Código de Comercio. Diario Oficial No. 33.339. Presidencia de la República, junio de 1971.

Decretos 1400 y 2019 de 1970. Por los cuales se expide el Código de Procedimiento Civil. Diario Oficial No. 33.150. Presidencia de la República, septiembre de 1970.

Díez-Picazo, L. (2008). Fundamentos del Derecho Civil patrimonial (Tomo 2, Las relaciones obligatorias, $6^{\mathrm{a}}$ ed.). Cizur Menor: Thomson Civitas.

Díez-Picazo, L., Roca, E., \& Morales, A. (2002). Los principios del Derecho europeo de contratos. Madrid: Civitas.

Fadda, R. (2005). L'aliud pro alio. En V. Buonacore \& A. Luminoso (Eds.), Codice della vendita ( $2^{\mathrm{a}}$ ed.) (pp. 605-612). Milán: Giuffrè.

Fenoy, N. (1996). Falta de conformidad e incumplimiento en la compraventa. (Evolución del ordenamiento español). Madrid: Colegio de Registradores de la Propiedad y Mercantiles de España; Centro de Estudios Registrales.

Gabrielli, E. (1987). La consegna di una cosa diversa. Nápoles: Jovene.

Ghestin, J. (1983). Conformité et garanties dans la vente (Produits mobiliers). Paris: LGDJ.

Greco, P., \& Cottino, G. (1981). Della Vendita. En A. Sciajola \& G. Branca (Eds.), Commentario del Codice Civile a cura di (2 $2^{\mathrm{a}}$ ed.). Roma: Zanichelli.

Illescas, R., \& Perales, P. (2003). Derecho Mercantil Internacional. El Derecho uniforme. Madrid: Editorial Centro de Estudios Ramón Areces S.A.
Industria panificadora El Arbolito vs. Wetson, (1991, Septiembre 11). Acción de declaración de incumplimiento, resolutoria e indemnizatoria. Corte Suprema de Justicia.

Larenz, K. (2010). Metodología de la ciencia del Derecho ( $2^{\mathrm{a}}$ ed.). Barcelona: Ariel Derecho.

Ley 57 de 1887. Sobre adopción de códigos y unificación de la legislación nacional: Código Civil. Diarios Oficial No. 7019. Consejo Nacional legislativo, abril de 1887.

Ley 518 de 1999. Por medio de la cual se aprueba la "Convención de las Naciones Unidas sobre los contratos de compraventa internacional de mercaderías", hecha en Viena el once (11) de abril de mil novecientos ochenta (1980). Diario Oficial No. 43.656. Congreso de la República de Colombia, agosto 1999.

Ley 1480 de 2011. Por medio de la cual se expide el Estatuto del Consumidor y se dictan otras disposiciones. Diario Oficial No. 48.220. Congreso de la República, octubre de 2011 .

Ley 1564 de 2012. Por medio de la cual se expide el Código General del Proceso y se dictan otras disposiciones. Diario oficial No. 48.489. Congreso de la República, junio de 2012.

Lombardi, E. M. (2010). Garanzia e responsabilità nella vendita del beni di consumo. Milán: Giuffrè.

Luminoso, A. (2009). La compravendita (6 ed.). Turín: Giappichelli.

Mantilla, F. (2013). La garantía de buen funcionamiento de la cosa vendida en el Código de Comercio colombiano. Foro de Derecho Mercantil, 38, 93-118. 
Mantilla, F., \& Ternera, F. (2008). Las acciones del comprador insatisfecho en el Derecho colombiano: un problema de incertidumbre jurídica. En F. Mantilla \& C. Pizarro (Coords.), Estudios de Derecho Privado en homenaje a Christian Larroumet. (pp. 299-326). Bogotá: Fundación Fernando Fueyo; Universidad Diego Portales; Universidad del Rosario.

Marco A. Pico vs. Manuel Neira M., (1952, marzo 27). Acción de declaración de incumplimiento y de ejecución forzosa de la obligación de entregar la cosa vendida. Corte Suprema de Justicia.

Martín, P. (2010). Las garantías de los productos de consumo. Cizur Menor: Aranzadi; Thomson Reuters.

Maza De la, I. (2012). El régimen de los cumplimientos defectuosos en la compraventa. Revista Chilena de Derecho Privado, 39(3), 629-663.

Messineo, F. (1979). Manual de Derecho Civil y Comercial (Tomo 6, Trad. S. SentisMelendo). Buenos Aires: Ediciones Jurídicas Europa América.

Morales, A. (1980). El alcance protector de las acciones edilicias. Anuario de Derecho Civil, 33(3), 585-686.

Morales, A. (1998). Artículo 35. En L. DiezPicazo \& P. León De (Dirs.), La compraventa internacional de mercaderías. Comentario de la Convención de Viena (pp. 286-312). Madrid: Civitas.

Morales, A. (2006a). Adaptación del Código Civil al Derecho Europeo: la compraventa. Anuario de derecho civil, 56(4), 93-144.

Morales, A. (Ed.) (2006b). La conformidad de la cosa vendida según la Directiva 1999/44/CE. En La modernización del
Derecho de obligaciones (pp. 161-188). Cizur Menor: Thomson Civitas.

Morales, A. (2012). Tres modelos de vinculación del vendedor en las cualidades de la cosa. Anuario de Derecho Civil, 65(1), 5-28.

M. R. Inversiones vs. Cooperativa agropecuaria del Meta. (1986, julio 23). Acción estimatoria e indemnizatoria. Corte Suprema de Justicia.

Nanclares, J. (2011). Unificación del Derecho Patrimonial europeo. Marco común de referencia y Derecho español. En E. Valpuesta (Comp.), Obligaciones y derechos (Vol. 3) (pp. 163 - 218). Valpuesta Barcelona: Bosch.

Navas, S. (2004). El incumplimiento no esencial de la obligación. Análisis del incumplimiento no esencial de las obligaciones contractuales de dar. Madrid: Reus.

Orti, A. (1987). La protección del comprador por el defecto de la cosa vendida. Granada: Ediciones TAT.

Ospina, G. (2001). Régimen general de las obligaciones ( $7^{\mathrm{a}} \mathrm{ed}$.). Bogotá: Temis.

Oviedo, J. (2010). Sobre el concepto de vicio redhibitorio en la compraventa. Análisis comparado de la jurisprudencia chilena y colombiana. Revista Chilena de Derecho, 37(2), 241-269.

Oviedo, J. (2012). La garantía por vicios ocultos en la compraventa. Análisis de Derecho Privado chileno y colombiano a la luz de las nuevas tendencias del Derecho de contratos (Tesis doctoral). Universidad de los Andes, Santiago de Chile.

Perales, P. (1996). La formación del contrato en la compraventa internacional de mercaderías. Valencia: Tirant lo Blanch. 
Pizarro, C. (2008). Hacia un sistema unificado de remedios al incumplimiento contractual. En A. Guzmán (Ed.), Estudios de Derecho Civil III, Jornadas nacionales de Derecho Civil Valparaíso 2007 (pp. 395402). Santiago: Pontificia Universidad Católica de Valparaíso; Legal Publishing.

Prats, L. (1992), La entrega de cosa diversa a la pactada (aliud pro alio) como incumplimiento resolutorio en la jurisprudencia del Tribunal Supremo (comentario a las sentencias del Tribunal Supremo de 1 de marzo de 1991, de 20 de noviembre de 1991 y 28 de enero de 1992). Revista General de Derecho, 573, 5081-5105.

Reino de España. Casimiro y María Milagros vs. Almudena y Tomás. (2006, octubre 31). Sentencia de apelación STS 1062. Sala de lo Civil, Tribunal Supremo.

República Italiana. Decreto Real 262 de 1942. Código Civil. Gaceta Oficial No. 79. Parlamento italiano, marzo de 1942.

Rodríguez, J. (2009). La oportunidad de saneamiento del incumplimiento del vendedor en el régimen de vicios materiales. Algunas reflexiones a partir del derecho alemán de la compraventa. Revista de Derecho Privado, 17, 107-140.

Rodríguez-Rosado, B. (2013). Resolución y sinalagma contractual. Madrid: Marcial Pons.

Savanna, L. (2007). La compravendita. Garanzia per vizi della cosa venduta e nuova tutela del consumatore. Turín: G. Giappichelli.

Schwenzer, I. (2010). Article 35. En P. Schlechtriem \& I. Schwenzer (Eds.), Commentary on the UN Convention on the international sale of goods (CISG) (pp. 568-594). Neva York: Oxford.
Schwenzer, I., Hachem, P., \& Kee, C. (2012). Global Sales and Contract Law. Neva York: Oxford.

Sociedad Marítimas Internacionales Ltda. vs. Caja de Crédito Agratio Industrial y Minero, Almacenes Generales de Depósito de la Caja Agraria, Idema, Banco Ganadero Almagrario S.A.- y Distribuidora Petrofert Ltda. (2010, diciembre 16). Acción indemnizatoria. Corte Suprema de Justicia.

Torsello, M. (2008). Italy. En F. Ferrari (Eds), The CISG and its Impact on National Legal Systems. Munich: Sellier.

Valencia, A., \& Ortiz, A. (2010). Derecho Civil (Tomo 3, De las obligaciones, $10^{\mathrm{a}}$ ed.). Temis: Bogotá.

Vaquer, A. (2011). El principio de conformidad: ¿Supraconcepto en el Derecho de obligaciones?. En K. Albiez, M. Palazón \& M. Méndez (Coords.), Derecho Privado europeo y modernización del Derecho contractual en España (pp. 369-399). Barcelona: Atelier.

Verda De, J. (2009). Saneamiento por vicios ocultos. Las acciones edilicias ( $2^{\mathrm{a}}$ ed.). Cizur Menor: Aranzadi.

Vidal, A. (2006). La protección del comprador. Régimen de la Convención de Viena y su contraste con el Código Civil. Valparaíso: Pontificia Universidad Católica de Valparaíso.

Vidal, A. (2007). Cumplimiento e incumplimiento contractual en el Código Civil. Una perspectiva más realista. Revista Chilena de Derecho, 34(1), 41-59.

Zimmermann, R. (1996). The Law of Obligations. Roman Foundations of the Civilian Tradition. Neva York: Oxford University Press. 